DOI: 10.20472/IAC.2017.029.021

\author{
YEN-LING LIN
}

Department of Economics, Tamkang University, Taiwan

\title{
AN EMPIRICAL ANALYSIS $\square$ ON RISK AVERSION AND EMPLOYMENT SECTOR
}

\begin{abstract}
:
This study investigates the effects of risk aversion on the choice of employment sector. We employ a joint model on employment sector choice and three dimensional background characteristics to show that employment preference is an inverse function of the degree of relative risk aversion. The empirical data is adopted from the Taiwan Education Panel Survey and Beyond. A logit model is applied to estimate the effects of three dimensional background characteristics on risk attitudes and employment choices. We find that individuals with a higher share of risky experiences are less risk averse and tend to choose the riskier employment sector.
\end{abstract}

\section{Keywords:}

employment sector, personality, risk aversion, Taiwan Education Panel Survey and Beyond, logit model

JEL Classification: J21, C33 